\title{
The reversibility of sea level rise
}

\author{
Article
}

Published Version

Bouttes, N., Gregory, J. M. and Lowe, J. A. (2013) The reversibility of sea level rise. Journal of Climate, 26 (8). pp. 2502-2513. ISSN 1520-0442 doi: https://doi.org/10.1175/JCLID-12-00285.1 Available at https://centaur.reading.ac.uk/34191/

It is advisable to refer to the publisher's version if you intend to cite from the work. See Guidance on citing.

To link to this article DOI: http://dx.doi.org/10.1175/JCLI-D-12-00285.1

Publisher: American Meteorological Society

All outputs in CentAUR are protected by Intellectual Property Rights law, including copyright law. Copyright and IPR is retained by the creators or other copyright holders. Terms and conditions for use of this material are defined in the End User Agreement.

\section{www.reading.ac.uk/centaur}

\section{CentAUR}

Central Archive at the University of Reading

Reading's research outputs online 


\title{
The Reversibility of Sea Level Rise
}

\author{
N. BOUTTES \\ NCAS-Climate, University of Reading, Reading, United Kingdom \\ J. M. GREGORY \\ NCAS-Climate, University of Reading, Reading, and Met Office Hadley Center, Exeter, United Kingdom \\ J. A. LOWE \\ Met Office Hadley Center, Exeter, United Kingdom
}

(Manuscript received 17 May 2012, in final form 20 September 2012)

\begin{abstract}
During the last century, global climate has been warming, and projections indicate that such a warming is likely to continue over coming decades. Most of the extra heat is stored in the ocean, resulting in thermal expansion of seawater and global mean sea level rise. Previous studies have shown that after $\mathrm{CO}_{2}$ emissions cease or $\mathrm{CO}_{2}$ concentration is stabilized, global mean surface air temperature stabilizes or decreases slowly, but sea level continues to rise. Using idealized $\mathrm{CO}_{2}$ scenario simulations with a hierarchy of models including an AOGCM and a step-response model, the authors show how the evolution of thermal expansion can be interpreted in terms of the climate energy balance and the vertical profile of ocean warming. Whereas surface temperature depends on cumulative $\mathrm{CO}_{2}$ emissions, sea level rise due to thermal expansion depends on the time profile of emissions. Sea level rise is smaller for later emissions, implying that targets to limit sea level rise would need to refer to the rate of emissions, not only to the time integral. Thermal expansion is in principle reversible, but to halt or reverse it quickly requires the radiative forcing to be reduced substantially, which is possible on centennial time scales only by geoengineering. If it could be done, the results indicate that heat would leave the ocean more readily than it entered, but even if thermal expansion were returned to zero, the geographical pattern of sea level would be altered. Therefore, despite any aggressive $\mathrm{CO}_{2}$ mitigation, regional sea level change is inevitable.
\end{abstract}

\section{Introduction}

Model-based studies have explored the evolution of climate in scenarios where atmospheric $\mathrm{CO}_{2}$ concentrations rise at various rates, following which $\mathrm{CO}_{2}$ is stabilized or the emissions are stopped (Meehl et al. 2005; Plattner et al. 2008; Solomon et al. 2009; Frölicher and Joos 2010; Gillett et al. 2011). In the latter case, global mean surface air temperature subsequently stays approximately constant or declines slowly as $\mathrm{CO}_{2}$ is removed from the atmosphere by natural processes. In some scenarios, including the later part of the policyrelevant Representative Concentration Pathway 2.6

Corresponding author address: Nathaelle Bouttes, NCAS-Climate, Meteorology Department, University of Reading, Reading, RG66BB, United Kingdom.

E-mail: n.bouttes@reading.ac.uk
(RCP2.6; Moss et al. 2010), which will be assessed in the next report of the Intergovernmental Panel on Climate Change (IPCC), $\mathrm{CO}_{2}$ is assumed to be artificially removed from the atmosphere at greater rates than natural uptake, producing a faster reduction in forcing and a faster cooling. However, sea level from thermal expansion continues to rise for many centuries following a stabilization of $\mathrm{CO}_{2}$ concentration in the atmosphere or a cessation of $\mathrm{CO}_{2}$ emissions (Meehl et al. 2005; Lowe et al. 2006; Plattner et al. 2008; Solomon et al. 2009; Frölicher and Joos 2010; Gillett et al. 2011). This raises the question of what it would take to reverse sea level rise.

In this work, we use a 3D atmosphere-ocean general circulation model (AOGCM) to explore how the emissions pathway affects the peak sea level and the subsequent decline. For simplicity, we consider $\mathrm{CO}_{2}$-only scenarios, since $\mathrm{CO}_{2}$ is the dominant forcing. We consider only the global mean thermosteric sea level, and 
not the additional component from glaciers and the ice sheets of Greenland and Antarctica (Charbit et al. 2008; Ridley et al. 2009; Vizcaíno et al. 2010; Huybrechts et al. 2011). The thermosteric term is influenced by ocean interior transport processes, including large-scale oceanic circulations such as the Atlantic meridional overturning circulation (AMOC). In the deep ocean, temperature changes caused by these processes occur on a hundred- to thousand-year time scale. Although this is slow, the thermosteric sea level change may be reversed more quickly than ice sheet mass loss, which would require a longer time scale of thousands of years (Charbit et al. 2008; Ridley et al. 2009). Likewise, reversing the sea level change induced by glaciers and ice caps would be a slower process. Thermosteric sea level change is subject to less (though still substantial) scientific uncertainty than ice sheets and glaciers, and is sufficient alone to cause significant sea level rise impacts for many centuries into the future.

\section{Method}

We run simulations with the Fast Met Office/UK Universities Simulator (FAMOUS) AOGCM (Smith et al. 2008). FAMOUS is a low-resolution version of the third climate configuration of the Met Office Unified Model (HadCM3) AOGCM (Gordon et al. 2000): its atmosphere component runs on a $5^{\circ}$ latitude by $7.5^{\circ}$ longitude grid with 11 levels and its ocean component on a $2.5^{\circ}$ latitude by $3.75^{\circ}$ longitude grid with 20 levels. It is structurally almost identical to HadCM3 and produces climate and climate-change simulations that are reasonably similar to HadCM3, but runs about 20 times faster and is hence particularly useful for investigations involving many long integrations. Despite the coarse resolution, the present-day climatology of FAMOUS is adequate without flux correction.

The simulations employ idealized scenarios in which atmospheric $\mathrm{CO}_{2}$ is first increased and then either held constant or abruptly decreased. The increase follows three pathways (Fig. 1a): an instantaneous increase of $\mathrm{CO}_{2}$ to 4 times the preindustrial value $\left(4 \times \mathrm{CO}_{2}\right.$; the preindustrial value is $280 \mathrm{ppm}$ ), a $1 \%$ increase of $\mathrm{CO}_{2} \mathrm{yr}^{-1}\left(1 \% \mathrm{CO}_{2}\right)$ for $140 \mathrm{yr}$, and a $2 \%$ increase of $\mathrm{CO}_{2} \mathrm{yr}^{-1}\left(2 \% \mathrm{CO}_{2}\right)$ for $70 \mathrm{yr}$. Both the $1 \% \mathrm{CO}_{2}$ and $2 \% \mathrm{CO}_{2}$ ramps end at 4 times the preindustrial value. Thus, at $t=140 \mathrm{yr}$ the $\mathrm{CO}_{2}$ concentration is the same in all scenarios, but the three pathways that have led to that level differ. Beyond $t=140 \mathrm{yr}$ the $\mathrm{CO}_{2}$ concentration is either kept constant at this value or instantaneously reduced, to either the preindustrial value $\left(1 \times \mathrm{CO}_{2}\right)$ or half of it $\left(0.5 \times \mathrm{CO}_{2}\right)$, and then held constant at the reduced value; in section $4 \mathrm{c}$ we also consider a scenario in which $\mathrm{CO}_{2}$ is ramped down. We consider these idealized

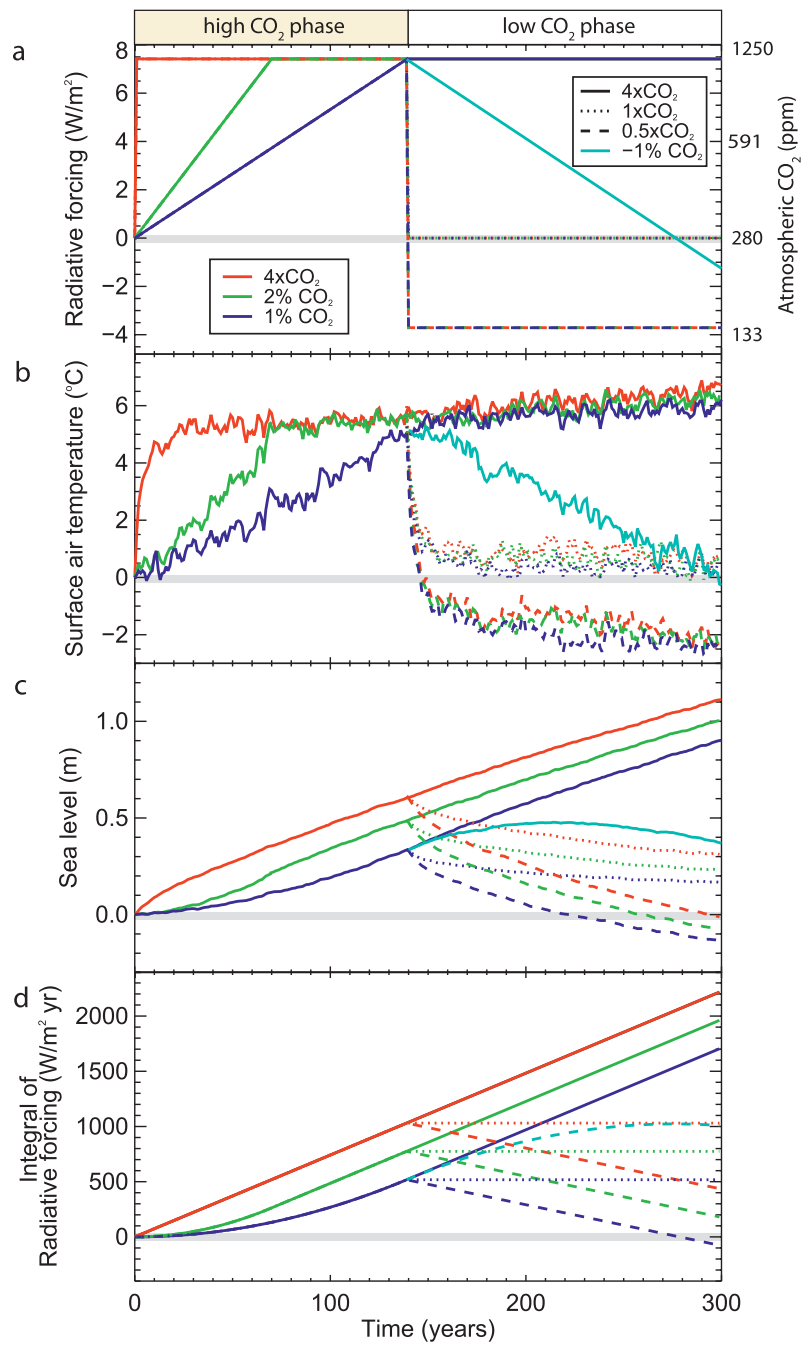

FIG. 1. Time series of radiative forcing due to the change of atmospheric $\mathrm{CO}_{2}$ and climate response. (a) Evolution of radiative forcing due to the atmospheric $\mathrm{CO}_{2}$ change in the simulations $\left(\mathrm{W} \mathrm{m}^{-2}\right)$, (b) evolution of the global mean surface air temperature anomaly $\left({ }^{\circ} \mathrm{C}\right)$, (c) evolution of the global mean thermosteric sea level anomaly (m), and (d) evolution of the time integral of the radiative forcing $\left(\mathrm{W} \mathrm{m}^{-2} \mathrm{yr}^{-1}\right)$. The anomalies are between the simulation and the control.

scenarios because they give a clear demonstration of the qualitative behavior of sea level. In particular, this is the reason for choosing the $0.5 \times \mathrm{CO}_{2}$ concentration (140 ppm), which is of course unrealistic for natural carbon sinks, being lower than the concentration at glacial maxima such as during the Last Glacial Maximum (atmospheric $\mathrm{CO}_{2}$ concentration of around 190 ppm approximately $21000 \mathrm{yr}$ ago).

As the $\mathrm{CO}_{2}$ concentrations scenarios are idealized, they are not evaluated in terms of feasibility or corresponding emissions. For the latter, a coupled carbon-climate model would be needed, which would include the fact that if 
emissions are cut to zero, the biosphere and ocean would progressively take up less carbon as they saturate. This would suggest that to achieve the assumed rates of $\mathrm{CO}_{2}$ reduction, actively removing $\mathrm{CO}_{2}$ from the atmosphere by artificial means may be needed, since the $\mathrm{CO}_{2}$ would otherwise stay in the atmosphere for a long time (several thousand years; Eby et al. 2009). The reduction of forcing does not necessary requires $\mathrm{CO}_{2}$ reduction and could possibly be obtained by other suggested geoengineering mechanisms (Shepherd et al. 2009), but the feasibility of this is not further discussed here.

We calculate sea level rise due to thermal expansion from ocean temperature change diagnosed from the model. As found previously (Russell et al. 2000), global mean thermosteric sea level rise $\eta$ and global mean ocean temperature rise $T_{o}$ (equivalent to the increase in ocean heat content) are in a nearly linear relationship (Fig. 2) and so we speak of them interchangeably. In the following sections, we interpret the qualitative features of results of the AOGCM for surface air temperature and sea level change using a range of simpler models (summarized in Table 1).

\section{Surface air temperature change}

During the first part of the simulations (the "high- $\mathrm{CO}_{2}$ phase"), while the atmospheric $\mathrm{CO}_{2}$ concentration is

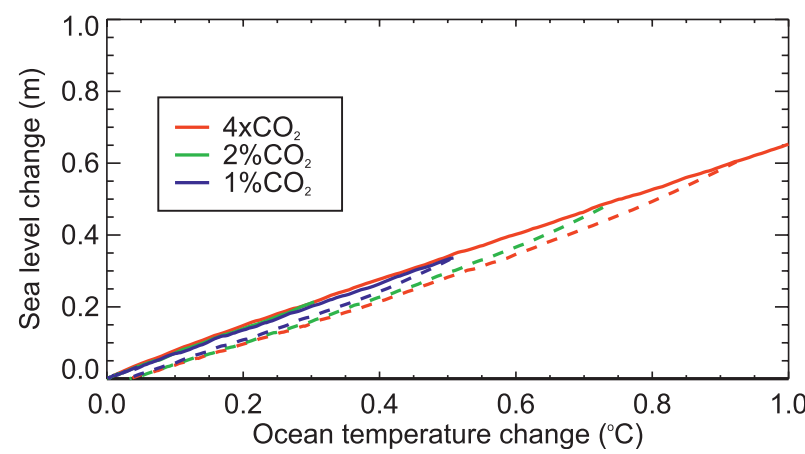

FIG. 2. Sea level change $(\mathrm{m})$ as a function of the global mean ocean temperature change $\left({ }^{\circ} \mathrm{C}\right)$. Slope $=0.66 \mathrm{~m}^{\circ} \mathrm{C}^{-1}$, for the $4 \times \mathrm{CO}_{2}, 2 \% \mathrm{CO}_{2}$, and $1 \% \mathrm{CO}_{2}$ simulations. The dashed lines indicate the results for the corresponding $0.5 \times \mathrm{CO}_{2}$ simulations described in Fig. 1.

increasing, the change of global mean surface air temperature $T_{s}$ tracks the $\mathrm{CO}_{2}$ concentration (Figs. 1a,b). In the case where the $\mathrm{CO}_{2}$ concentration is instantaneously increased, $T_{s}$ takes a couple of decades to respond. After $140 \mathrm{yr}, T_{s}$ is the same in the three simulations. It has similarly been shown that, under scenarios in which emissions peak and decline, the peak warming attained depends only on the cumulative $\mathrm{CO}_{2}$ emission and is largely insensitive to the emissions pathway up to the time of maximum temperature (Allen et al. 2009a; Matthews et al. 2009; Zickfeld et al. 2009; Bowerman et al. 2011).

TABLE 1. Summary of the main results from the models.

\begin{tabular}{|c|c|c|}
\hline Model & \multicolumn{2}{|c|}{ Main features of the results } \\
\hline \multirow[t]{2}{*}{$\begin{array}{r}\text { FAMOUS AOGCM } \\
\text { (Smith et al. 2008) }\end{array}$} & $\begin{array}{l}\text { Sea level evolution depends on the emissi } \\
\text { Sea level continues to rise after stabilizati } \\
\text { Sea level rise is reversed if forcing becom } \\
\text { Sea level rise and fall are not symmetric }\end{array}$ & $\begin{array}{l}\text { on pathway } \\
\text { on } \\
\text { es zero or negative }\end{array}$ \\
\hline & Successfully explains & Fails to explain \\
\hline $\begin{array}{l}\text { Zero-layer model } \\
\text { (Gregory and Mitchell 1997; Raper } \\
\quad \text { et al. 2002; Gregory and Forster } \\
\text { 2008; Held et al. 2010) } \\
\text { Surface climate energy balance }\end{array}$ & $\begin{array}{l}\text { Sea level rise depends on the emission } \\
\text { pathway } \\
\text { Sea level continues to rise after } \\
\text { stabilization }\end{array}$ & $\begin{array}{l}\text { Sea level rise can be reversed without negative } \\
\text { forcing (the model assumes heat loss into an } \\
\text { infinite heat sink that does not warm up and } \\
\text { therefore does not give back heat spontaneously) }\end{array}$ \\
\hline $\begin{array}{l}\text { Two-layer model } \\
\text { (Gregory 2000; Held et al. 2010) } \\
\text { Has an upper layer with small heat } \\
\text { capacity and a lower layer with } \\
\text { large heat capacity; the layers are } \\
\text { thermally coupled }\end{array}$ & $\begin{array}{l}\text { Features explained successfully by the } \\
\text { zero-layer model } \\
\text { Sea level rise is reversible: it falls during } \\
\text { low- } \mathrm{CO}_{2} \text { phase (the model is able to } \\
\text { distinguish surface temperature from } \\
\text { heat content and can lose heat } \\
\text { spontaneously) }\end{array}$ & $\begin{array}{l}\text { Asymmetry of the sea level fall and rise (the single } \\
\text { lower layer has too much heat capacity and does } \\
\text { not warm up very much, so heat flux depends } \\
\text { almost entirely on the upper temperature) }\end{array}$ \\
\hline $\begin{array}{l}\text { Step model } \\
\text { (Good et al. 2011) } \\
\text { Uses the diagnosed 3D response of } \\
\text { FAMOUS to } 4 \times \mathrm{CO}_{2}\end{array}$ & $\begin{array}{l}\text { Features explained successfully by the } \\
\text { two-layer model. } \\
\text { Part of the asymmetry between the sea } \\
\text { level fall and rise (because of multiple } \\
\text { layers in the ocean) }\end{array}$ & $\begin{array}{l}\text { Remaining part of the asymmetry (due to the } \\
\text { different penetration of heat during warming } \\
\text { and cooling, because the step model does not } \\
\text { have any functional dependence on vertical } \\
\text { stability) }\end{array}$ \\
\hline
\end{tabular}


The second part of the simulations (the "low- $\mathrm{CO}_{2}$ phase") begins at year 141, when the $\mathrm{CO}_{2}$ concentration is either stabilized or lowered. After $\mathrm{CO}_{2}$ stabilizes, the rate of surface air temperature increase is greatly reduced (Fig. 1b). If the radiative forcing abruptly returns to zero, $T_{s}$ falls most of the way to zero within around two decades. If $\mathrm{CO}_{2}$ is set to a value smaller than the initial one, the radiative forcing becomes negative, and $T_{s}$ falls below its initial value. It is apparent that $T_{s}$ depends roughly linearly on the forcing (Figs. $1 \mathrm{a}$ and $1 \mathrm{~b}$ are similar in form), as can be understood from simple "zerolayer" heat balance equations for time-dependent climate change (Gregory and Mitchell 1997; Raper et al. 2002; Gregory and Forster 2008; Held et al. 2010; see Table 1):

$$
F=(\alpha+\kappa) T_{s} \Rightarrow T_{s}=\frac{F}{\alpha+\kappa},
$$

where $\alpha$ is the climate feedback parameter, $\kappa$ is the ocean heat uptake efficiency, and the radiative forcing $F$ depends roughly linearly (actually logarithmically) on the atmospheric $\mathrm{CO}_{2}$ concentration $C$. In this zero-layer model, there is no feedback of ocean temperature on the rate of heat uptake and the ocean is effectively infinitely deep (i.e., it can absorb heat indefinitely).

$C$ is equivalent to the increase in the $\mathrm{CO}_{2}$ burden of the atmosphere ( $1 \mathrm{GtC} \equiv 0.47 \mathrm{ppm})$. Hence $C$ is determined uniquely at each time by the cumulative $\mathrm{CO}_{2}$ emissions $E$ through the relationship $C=A E$, provided the airborne fraction $A$ is constant. Observations indicate that $A$ has been approximately constant during recent decades (Knorr 2009), but it could change in the future (Friedlingstein et al. 2006). How much it might change appears to depend on both the emissions scenario (Gloor et al. 2010) and the behavior of the carbon cycle (Friedlingstein et al. 2006), which is uncertain. For the shapes of scenario considered here, and assuming that a linear model provides a reasonable first-order representation of the carbon cycle (Joos et al. 1996), then we would expect a constant value of $A$ to also be an acceptable approximation. If so, $T_{s}$ will track $E$ (Matthews et al. 2009; Gregory et al. 2009).

\section{Sea level change}

\section{a. Dependence of sea level rise on the pathway of emissions}

Sea level behaves qualitatively differently from $T_{s}$. The evolution of sea level rise due to thermal expansion depends on the pathway of emissions (Stouffer and Manabe 1999; Zickfeld et al. 2012) and reaches different values at 140 years despite the $\mathrm{CO}_{2}$ concentration and $T_{s}$ being the same at that time (Fig. 1c). Comparing Figs. 1c and $1 \mathrm{~d}$, we see that sea level rise depends almost linearly on the integral of the radiative forcing while the forcing is positive (high- $\mathrm{CO}_{2}$ phase). This is consistent with the zero-layer model, in which the rate of ocean heat uptake $N$ is proportional to $T_{s}$,

$$
N=\kappa T_{s}=F \times \frac{\kappa}{\alpha+\kappa},
$$

and hence the rate of sea level depends on $F$. However, the actual sea level rise is given by

$$
\eta \propto \int N d t=\int F \times \frac{\kappa}{\alpha+\kappa} d t=\frac{\kappa}{\alpha+\kappa} \int F d t,
$$

provided $\kappa$ and $\alpha$ are constant (Gregory and Forster 2008).

Thus, because the thermosteric sea level is proportional to the time integral of the radiative forcing, the longer the forcing lasts, the bigger the change in thermosteric sea level rise (and oceanic temperature). The sea level change is the largest in the simulation where the largest fractional increase in the atmospheric burden of $\mathrm{CO}_{2}$ occurs the earliest, which implies where $\mathrm{CO}_{2}$ has been emitted the earliest. Because of a focus on impacts related to peak warming, it has been proposed that policy targets for avoiding dangerous climate change might be set in terms of cumulative $\mathrm{CO}_{2}$ emission (Allen et al. 2009b). However, if we are concerned with mitigating sea level impacts, targets must be set on the rate of emission as well.

\section{b. Long-term commitment to sea level rise}

If $\mathrm{CO}_{2}$ is stabilized, ocean temperature and sea level continue to rise (Fig. 1c), in contrast to $T_{s}$ (Fig. 1b). After the $\mathrm{CO}_{2}$ concentration is stabilized, because $T_{s}$ is approximately the same in the three stabilization simulations (Fig. $1 \mathrm{~b} ; \sim 5.5^{\circ} \mathrm{C}$ ), the rate of thermosteric sea level rise is nearly the same in all three. That is, the three solid lines in Fig. 1c are nearly parallel; the rate is $\sim 4 \mathrm{~mm} \mathrm{yr}^{-1}$, much higher than the recent rate of $0.9 \mathrm{~mm} \mathrm{yr}^{-1}$ for 1993-2008 (Church et al. 2011). Thus the zero-layer model still explains the evolution of both temperature and sea level in the AOGCM for at least a century after stabilization of the $\mathrm{CO}_{2}$ concentration.

\section{c. Reversibility of sea level rise}

The experiments with stabilized $\mathrm{CO}_{2}$ may give an impression that sea level rise is irreversible, but if $\mathrm{CO}_{2}$ is returned instantaneously to its initial value, sea level immediately falls, albeit at a slow and decreasing rate so that after 160 years it has fallen only half the way to its initial level. Any practical measures to remove $\mathrm{CO}_{2}$ 
from the atmosphere would produce a gradual rather than an instantaneous decrease; if $\mathrm{CO}_{2}$ is ramped down, the oceanic temperature initially continues to rise, then gradually stabilizes, and then begins to fall. This is illustrated by a simulation in which $\mathrm{CO}_{2}$ increases at $1 \% \mathrm{yr}^{-1}$ for $140 \mathrm{yr}$ and then decreases at $1 \% \mathrm{yr}^{-1}$ for the next $140 \mathrm{yr}$ (cyan lines in Fig. 1). In this experiment the time-integral forcing is the same as in the scenario of $4 \times \mathrm{CO}_{2}$ followed by $1 \times \mathrm{CO}_{2}$ (dotted red lines); the later reduction in $\mathrm{CO}_{2}$ means that sea level is higher following the ramp-down. If the radiative forcing becomes negative (dashed lines), sea level falls back more rapidly to its initial value. Thus, sea level rise is in principle reversible, provided that the radiative forcing is reduced sufficiently. A long-term multicentury commitment to rising thermal expansion is not physically inevitable, although it may be practically so.

However, the zero-layer model fails to explain the sea level reversibility in the AOGCM. Since the sea level rise is proportional to the integral of the forcing $F$, it predicts that sea level will remain constant if the forcing is returned to zero, and will fall only if a negative forcing is applied. The zero-layer model assumes heat loss into an infinite heat sink that does not warm up and therefore does not give back heat spontaneously. It cannot account for sea level falling under zero forcing because it neglects changes happening below the ocean surface layer. In reality, the ocean is finite and more than one time scale is relevant. The rapid time scale of one or two decades relates to the ocean surface layer and accounts for most of the response of surface air temperature to the radiative forcing following abrupt change in $\mathrm{CO}_{2}$. The time scale of the "recalcitrant" response (Held et al. 2010) is another time scale that applies to the evolution of sea level.

This can be illustrated with a two-layer model (Gregory 2000; Held et al. 2010; Table 1). The two-layer model is composed of an ocean with an upper layer of thickness $d_{u}$ $(100 \mathrm{~m})$ and temperature $T_{u}$, and a deep layer of thickness $d_{l}(2000 \mathrm{~m})$ and temperature $T_{l}$, where both temperature are perturbations from an equilibrium with zero surface heat flux. The upper layer has little heat capacity and plays the role of a regulator; it absorbs the forcing, determines the radiation of heat to space, and is thermally coupled to the lower layer, which has large heat capacity and provides inertia. The heat flux between the two is proportional to their temperature difference. The temperatures thus follow the two equations

$$
\begin{aligned}
& c d_{u} \frac{d T_{u}}{d t}=F-c k \frac{\left(T_{u}-T_{l}\right)}{0.5 \times\left(d_{l}+d_{u}\right)}-\alpha T_{u} \quad \text { and } \\
& c d_{l} \frac{d T_{l}}{d t}=c k \frac{\left(T_{u}-T_{l}\right)}{0.5 \times\left(d_{l}+d_{u}\right)},
\end{aligned}
$$
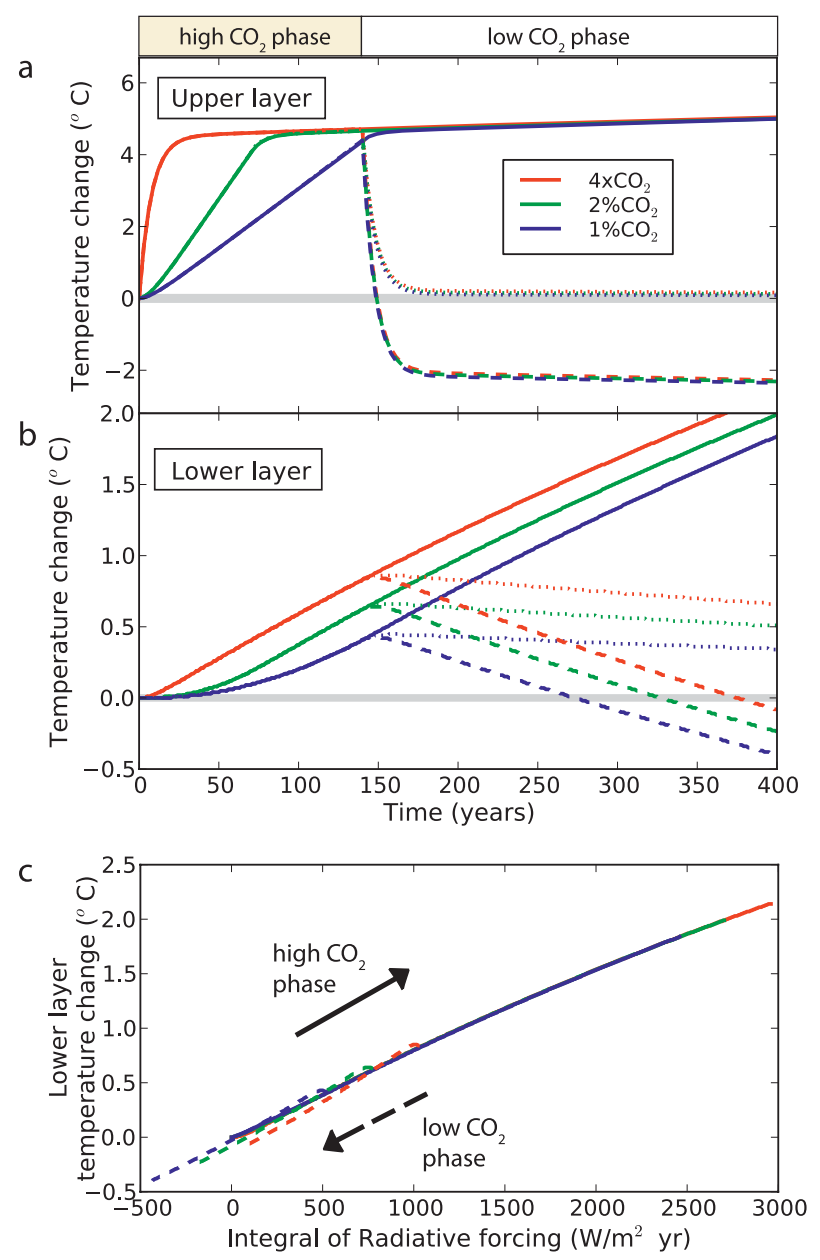

FIG. 3. Time series of the climate response to the same radiative forcing change as in Fig. 1 with the two-layer model. (a) Evolution of the upper ocean layer temperature anomaly $\left({ }^{\circ} \mathrm{C}\right),(\mathrm{b})$ evolution of the lower ocean layer temperature anomaly $\left({ }^{\circ} \mathrm{C}\right)$, and $(\mathrm{c})$ lower ocean layer temperature change $\left({ }^{\circ} \mathrm{C}\right)$ as a function of the integral of the radiative forcing during the phase with high $\mathrm{CO}_{2}$ (solid lines) and continuing under $0.5 \times \mathrm{CO}_{2}$ (dashed lines).

with $c=4.218 \times 10^{6} \mathrm{~J} \mathrm{~m}^{-3} \mathrm{~K}^{-1}$ being the volumetric heat capacity, $F\left(\mathrm{~W} \mathrm{~m}^{-2}\right)$ the surface heat flux, $k=$ $1 \times 10^{-4} \mathrm{~m}^{2} \mathrm{~s}^{-1}$ the thermal diffusivity, and $\alpha=$ $0.81 \mathrm{~W} \mathrm{~m}^{-2} \mathrm{~K}^{-1}$ the climate feedback parameter.

When the radiative forcing $F$ changes abruptly, $T_{u}$ rapidly reaches a new near-equilibrium (Fig. 3a), in which $F$ is nearly balanced by transfer of heat to or from the lower layer. If $F$ reverts to zero, the upper layer rapidly becomes cooler than the lower layer, which therefore loses heat (Fig. 3b, dotted lines). If a negative forcing is applied, the upper layer gets still colder, the temperature difference between the two layers is greater, the transfer of heat from the lower to the upper ocean is faster, and the lower layer cools down more rapidly (Fig. 3b, dashed lines). Unlike the zero-layer model, 


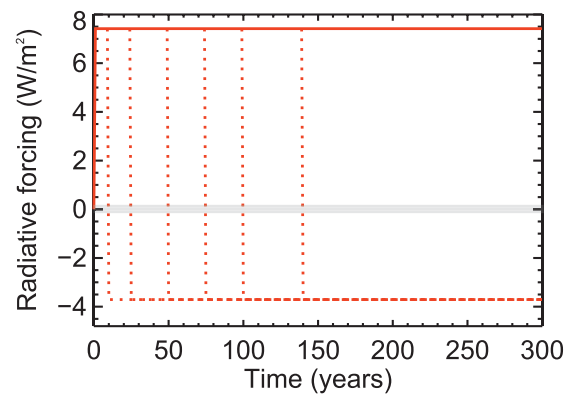

C

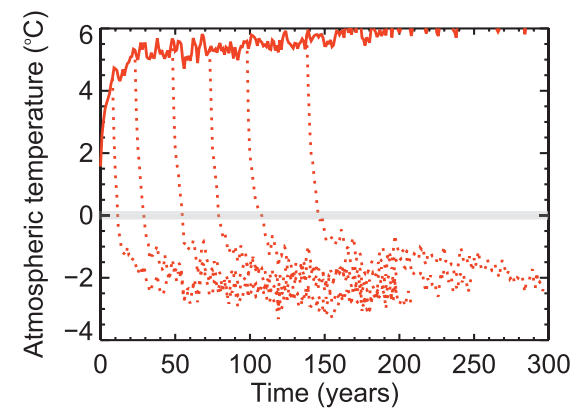

e

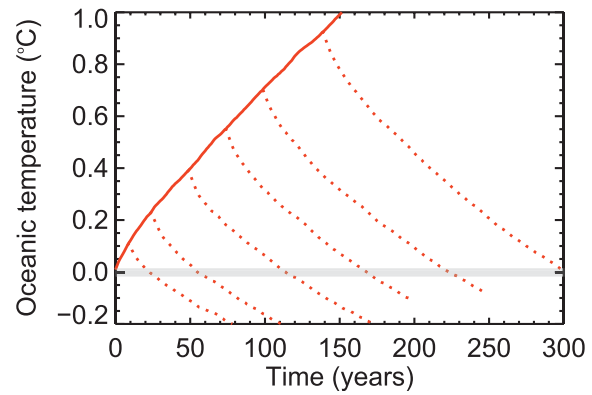

b

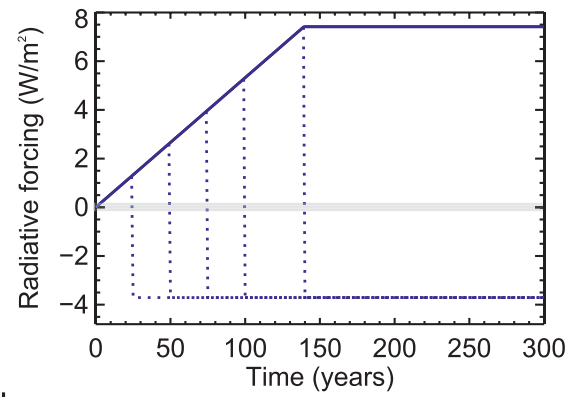

d

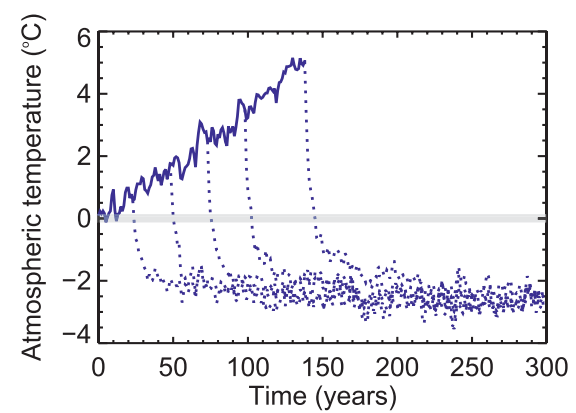

f

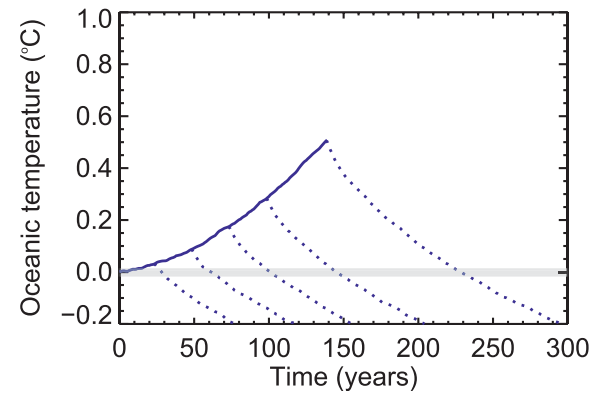

FIG. 4. (a),(b) Atmospheric $\mathrm{CO}_{2}$ (ppm), (c),(d) global mean surface air temperature $\left({ }^{\circ} \mathrm{C}\right)$ and (e),(f) global mean oceanic temperature $\left({ }^{\circ} \mathrm{C}\right)$ evolution in additional simulations in which $\mathrm{CO}_{2}$ is either (left) raised to $4 \times \mathrm{CO}_{2}$ and held constant for $140 \mathrm{yr}$ or (right) ramped up at $1 \% \mathrm{yr}^{-1}$ for $140 \mathrm{yr}$, and in either case lowered to $0.5 \times \mathrm{CO}_{2}$ at different times between 10 and $140 \mathrm{yr}$ and then held constant.

the two-layer model reproduces remarkably well these features of the evolution of surface temperature and thermosteric sea level in the much more complex AOGCM (Figs. 3a and $3 \mathrm{~b}$ are qualitatively very similar to Figs. $1 \mathrm{~b}$ and 1c). The two-layer model thus accounts for the reversibility of sea level rise when the radiative forcing diminishes because it has a finite ocean and the model is able to distinguish surface temperature from heat content so that it can lose heat spontaneously.

\section{d. Asymmetry of sea level evolution}

In the zero-layer model, the ocean temperature and sea level change should be back to zero when the integral of $F$ returns to zero (i.e., after a negative forcing of the same time integral as the one during the high- $\mathrm{CO}_{2}$ phase). For example, for the $1 \times \mathrm{CO}_{2}$ scenario followed by $0.5 \times \mathrm{CO}_{2}$, this is at $280 \mathrm{yr}$, but actually the sea level in the AOGCM reaches zero sooner, at $224 \mathrm{yr}$.

To quantify better the link between the ocean temperature change and the radiative forcing, we have run additional AOGCM simulations (Fig. 4), beginning with a high- $\mathrm{CO}_{2}$ phase of either constant $4 \times \mathrm{CO}_{2}$ or a $1 \% \mathrm{CO}_{2}$ ramp-up. In these simulations, $\mathrm{CO}_{2}$ is reduced abruptly to $0.5 \times \mathrm{CO}_{2}$ after various times between 10 and $100 \mathrm{yr}$ (instead of $140 \mathrm{yr}$ as in the scenario of Fig. 1).

During the low- $\mathrm{CO}_{2}$ phase, the time for the oceanic temperature to cool down to its initial value depends linearly on the oceanic warming achieved during the high- $\mathrm{CO}_{2}$ phase (Fig. 5a), and hence on the integral of the forcing during that phase (Fig. 5b). However, it takes less negative integral radiative forcing $F$ (or less time with a symmetrical forcing evolution) for the oceanic 

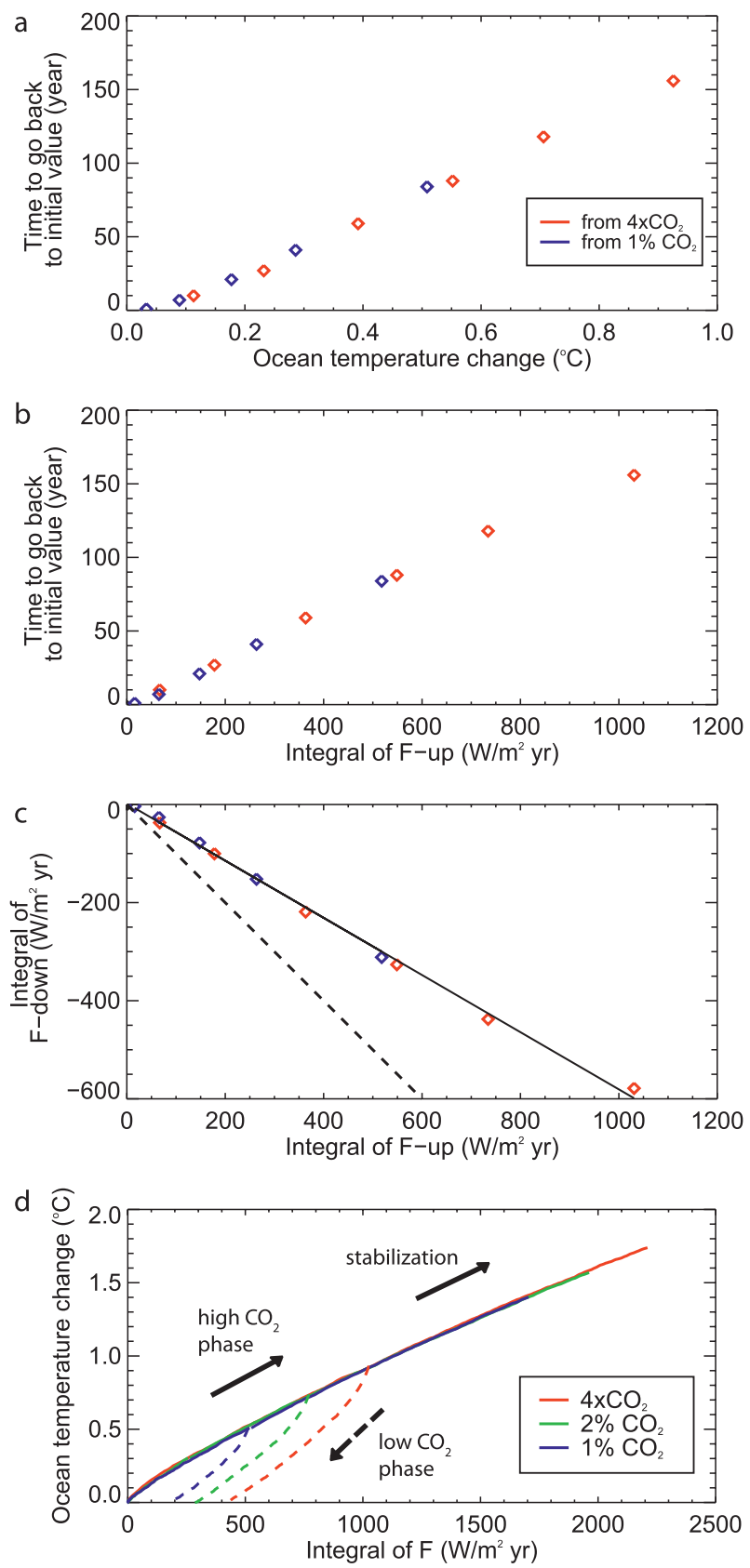

FIG. 5. Relations between (a) the time for the global mean ocean temperature change $T_{o}$ to return to its initial value under $0.5 \times \mathrm{CO}_{2}$ and $T_{o}$ at the time when $\mathrm{CO}_{2}$ is lowered to $0.5 \times \mathrm{CO}_{2}$, (b) the time for $T_{o}$ to return to its initial value under $0.5 \times \mathrm{CO}_{2}$ and the time integral of the radiative forcing during the phases with high $\mathrm{CO}_{2}$ (F-up), and (c) the integral of the radiative forcing during the phases with high $\mathrm{CO}_{2}$ (F-up) and during the phase with the low $\mathrm{CO}_{2}$ (F-down) up to the time at which $T_{o}$ returns to $0^{\circ} \mathrm{C}$. Each symbol is the result of one of the simulations in Fig. 3. The dotted line indicates where the symbols would align if the warming and cooling were symmetrical. The solid line is the linear fit with a slope of -0.58 . (d) Results from the simulations of Fig. 1 for global mean ocean temperature change $\left({ }^{\circ} \mathrm{C}\right)$ as a function of the integral of the radiative forcing during the phase with high $\mathrm{CO}_{2}$ and stabilization (solid lines) and continuing under $0.5 \times \mathrm{CO}_{2}$ (dashed lines). temperature to go back to its initial value (Fig. $5 \mathrm{c}$ ) $\left(\left|\int F_{\text {down }} d t\right|<\left|\int F_{\text {up }} d t\right|\right)$. Thus, the relationship between the oceanic temperature change and the integral of the forcing is different during the high- $\mathrm{CO}_{2}$ and low- $\mathrm{CO}_{2}$ phases (Fig. 5d). The amount of negative radiative forcing needed for the sea level to go back to its initial value is linearly related to the amount of positive radiative forcing:

$$
\left|\int F_{\text {down }} d t\right| \approx 0.58\left|\int F_{\text {up }} d t\right| \text {. }
$$

The numerical factor depends on the scenario and model.

Although it exhibits reversibility, the two-layer model cannot explain why the ocean cools down more effectively than it warms up. In the two-layer model, the relationship between ocean temperature and $\int F d t$ is the same in the high- $\mathrm{CO}_{2}$ and low- $\mathrm{CO}_{2}$ phases (Fig. 3c), unlike in the AOGCM (Fig. 5d). The lower layer is a very large well-mixed heat capacity that sets the long time scale for approach to a steady state. Consequently, the lower layer warms much less than the upper layer in the high phase (at $140 \mathrm{yr}$ in the $1 \%$ scenario, $T_{u}=4.4^{\circ} \mathrm{C}$ in Fig. 3a and $T_{l}=0.4^{\circ} \mathrm{C}$ in Fig. 3b). Because $T_{u}$ closely tracks $F$, and $T_{l} \ll T_{u}$, the heat flux $\propto T_{u}-T_{l}$ between the layers has roughly the same time profile as $F$, and $T_{l} \propto \int F d t$. Because the single lower layer has too much heat capacity and does not warm up very much, the heat flux depends almost entirely on the upper temperature and hence on the integral of the radiative forcing. More layers would be needed to explain the faster loss of heat during the low- $\mathrm{CO}_{2}$ phase.

To account for the asymmetry, we apply the stepresponse model of Good et al. (Good et al. 2011; Table 1). In this model, the evolution of any climate variable $X(t)$ is estimated by regarding it as the linear superposition of the responses to a succession of small instantaneous stepforcing changes $\delta F(t)$ in forcing, such that $F(t)=\int_{0}^{t} \delta F\left(t^{\prime}\right) d t^{\prime}$. We carry out a single AOGCM experiment in which $\mathrm{CO}_{2}$ is quadrupled at $t=0$, giving forcing $F\left(4 \times \mathrm{CO}_{2}\right)$, and then held constant. If $X=X_{4}(t)$ in this experiment, we estimate that $X(t)=\int_{0}^{t} X_{4}\left(t-t^{\prime}\right) \delta F\left(t^{\prime}\right) / F\left(4 \times \mathrm{CO}_{2}\right) d t^{\prime}$ - that is, a convolution of the response to the $4 \times \mathrm{CO}_{2}$ step with the forcing time series. Good et al. (2011) show that this method is accurate for surface temperature and has skill at reproducing ocean heat uptake. We use the step model to study the experiment with $1 \% \mathrm{CO}_{2}$ followed by $0.5 \times \mathrm{CO}_{2}$ as an example.

The step model successfully reproduces the evolution of the surface air temperature $T_{s}$ and ocean temperature $T_{o}$ during the high- $\mathrm{CO}_{2}$ phase (Figs. 6a,b). (Note that $T_{s}$ from the step model lacks the variability of the AOGCM because the convolution tends to smooth it 

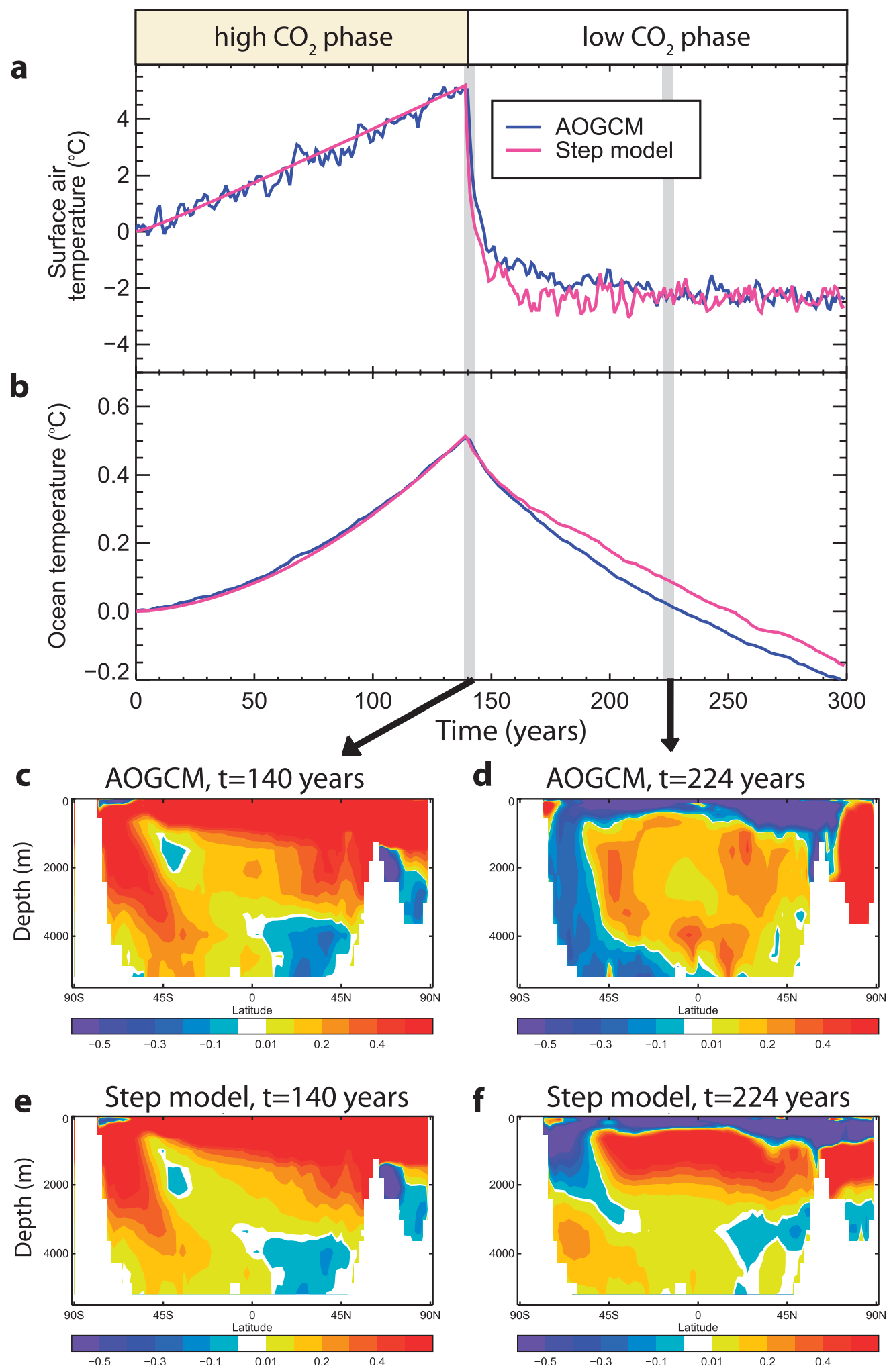

FIG. 6. Results for the climate response of the AOGCM and the step model in response to $1 \% \mathrm{CO}_{2}$ for $140 \mathrm{yr}$, then $0.5 \times \mathrm{CO}_{2}$. (top) Time series of (a) global mean surface air temperature and (b) global mean oceanic temperature. (c)-(f) zonal mean ocean temperature at (left) $t=140 \mathrm{yr}$ and (right) $t=224 \mathrm{yr}$ (when the mean oceanic temperature change is back to $\left.0^{\circ} \mathrm{C}\right)$, for (c),(d) the AOGCM and (e),(f) the step model. 


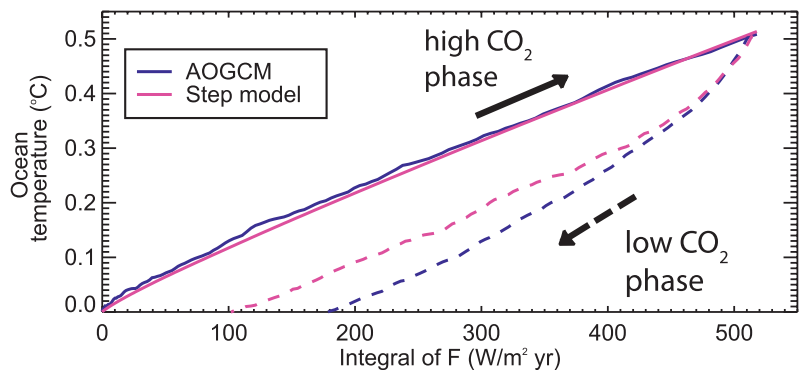

FIG. 7. Global mean ocean temperature change $\left({ }^{\circ} \mathrm{C}\right)$ as a function of the integral of the radiative forcing during the phase with high $\mathrm{CO}_{2}\left(1 \% \mathrm{CO}_{2}\right.$, solid lines) and continuing under $0.5 \times \mathrm{CO}_{2}$ (dashed lines).

out.) The step model estimate of the ocean temperature change latitude-depth distribution is also very good (cf. Figs. 6c,e), showing the warming spreading downward from the surface, with deeper penetration at high latitudes.

The step model gives a better approximation of the evolution during the low- $\mathrm{CO}_{2}$ phase than the zero- and two-layer models (Table 1). In particular, it correctly predicts that $T_{o}$ returns to its initial value before year 280 ; it is qualitatively superior to the two-layer model in partly reproducing the asymmetry between the warming and cooling phases (Fig. 7). This is because the step model, like the AOGCM, has many layers and time scales. Unlike in the two-layer model, the ocean below the surface is not well mixed. The shallower layers have relatively small heat capacity and warm substantially during the high- $\mathrm{CO}_{2}$ phase, and as time passes the warming spreads to deeper layers. During the low- $\mathrm{CO}_{2}$ phase, the shallow layers likewise cool rapidly. In the AOGCM, this causes a large temperature contrast between the newly cooled surface and previously warmed subsurface layers, which forces heat out of the ocean more rapidly than it entered. In the step model, the large temperature contrast and rapid heat loss are predicted as a consequence of the large negative step in forcing from $4 \times \mathrm{CO}_{2}$ to $0.5 \times \mathrm{CO}_{2}$. In both models, as a consequence of the high- $\mathrm{CO}_{2}$ phase, additional heat is still being transported to deeper layers during the low- $\mathrm{CO}_{2}$ phase at the same time as the cooling penetrates into the surface. In the global mean, similar qualitative behavior would be obtained from a vertical diffusion model of ocean temperature (e.g., Marčelja 2010). The advantages of the step model are that it can be applied in 3D, and that it emulates the AOGCM without any tuning of parameters being required.

However, the step model shows some inaccuracies. In particular, $T_{s}$ falls too quickly at the start (Fig. 6a), and after about 30 years the step model underestimates the oceanic cooling progressively more seriously (Fig. 6b). These phenomena can be linked: both are related to an insufficient heat flux from lower layers toward the surface. Correspondingly, the cooling anomaly does not penetrate as deeply at high latitudes in the step model as in the AOGCM simulation, while in middle and low latitudes the thermocline does not cool as quickly (cf. Figs. $6 \mathrm{~d}$ and $6 \mathrm{f}$ ). The asymmetry between high- $\mathrm{CO}_{2}$ and low$\mathrm{CO}_{2}$ phases is thus not as pronounced as in the AOGCM (Fig. 7).

We infer that these remaining discrepancies arise from nonlinear behavior of the AOGCM that the step model does not capture. In particular, the responses of the AOGCM to positive and negative step changes in forcing of equal magnitude are not equal and opposite (Fig. 8). This asymmetry cannot be captured by the step model, which is constructed by using the response to a positive step only, and presumably arises from the dependence of vertical heat transport on stability in the AOGCM (Stouffer and Manabe 1999). In particular, for the same absolute value of radiative forcing, the warming penetrates relatively deeper in the Arctic whereas
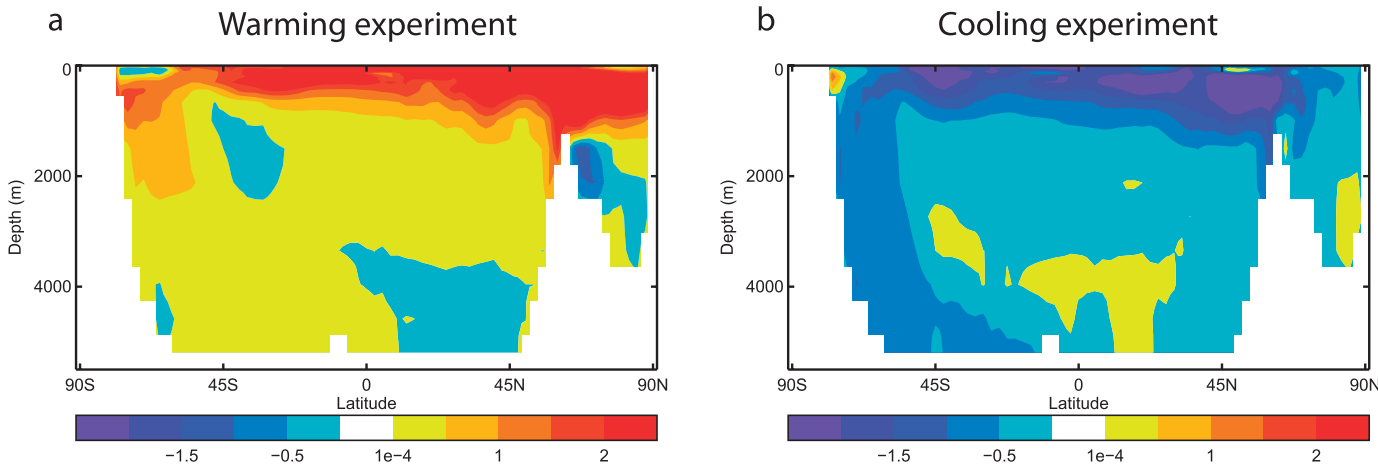

FIG. 8. Zonal-mean ocean temperature anomaly $\left({ }^{\circ} \mathrm{C}\right)$ as a function of depth after $70 \mathrm{yr}$ of simulation, (a) under $4 \times \mathrm{CO}_{2}$ (warming) and (b) under $0.25 \times \mathrm{CO}_{2}$ (cooling). Both simulations start from the same initial state. The anomaly is with respect to the control simulation. 
the cooling goes deeper in the Southern Ocean (Fig. 8). This different penetration of the heat anomaly during warming and cooling simulations has previously been described by Manabe et al. (1991), with similar results in the Southern Ocean but slightly different penetration of heat in the North Atlantic. After a sequence of warming $\left(1 \% \mathrm{CO}_{2}\right.$ experiment) followed by a cooling $\left(0.5 \times \mathrm{CO}_{2}\right.$ experiment), this different penetration of the heat anomaly results in a warmer Arctic and cooler Southern Ocean (except in the surface) in the AOGCM than in the step model at the time (224 years) when $T_{o}$ in the AOGCM is back to its initial value.

\section{e. Regional sea level changes}

Impacts of sea level change arise from its regional distribution. As shown in Fig. 6, even when the global mean ocean temperature is back to its initial value, heat in the ocean is distributed differently, with some areas warmer and others colder. This means that there is a still a regional pattern of thermosteric sea level change when $T_{o}$ returns to $0^{\circ} \mathrm{C}$ (Fig. 9). Although the global mean $\eta$ is $0 \mathrm{~m}$, sea level is higher than in the initial state in the Arctic and Atlantic south of $45^{\circ} \mathrm{N}$, and lower in the North Atlantic and southern Indian Ocean. This distribution is likely to be model dependent as the regional sea level change changes from model to model (Pardaens et al. 2011), but the same qualitative point would hold. Thus, even if it were practical to eliminate the commitment to global thermosteric sea level change by negative radiative forcing, the commitment to regional sea level change would be yet more recalcitrant.

\section{Conclusions}

We have studied the future evolution of global mean sea level rise due to thermal expansion (i.e., not including contributions from ice sheets and glaciers) with an AOGCM under idealized $\mathrm{CO}_{2}$ scenarios. Unlike surface temperature change, sea level change depends not only on the cumulative emission of $\mathrm{CO}_{2}$ but also on the emission pathway. A greater rise in sea level results from earlier emissions than from later, for the same cumulative emission. Hence, targets to limit sea level rise would need to refer to rates of emissions as well as the total.

Thermal expansion will continue for many centuries if $\mathrm{CO}_{2}$ emissions cease or if $\mathrm{CO}_{2}$ concentration is stabilized. However, it is in principle reversible. Reducing the radiative forcing sufficiently would halt or reverse it, and a negative forcing would reverse it more quickly. Of course, reducing the forcing would require removal of $\mathrm{CO}_{2}$ from the atmosphere or other geoengineering, which is not yet technologically feasible and might have

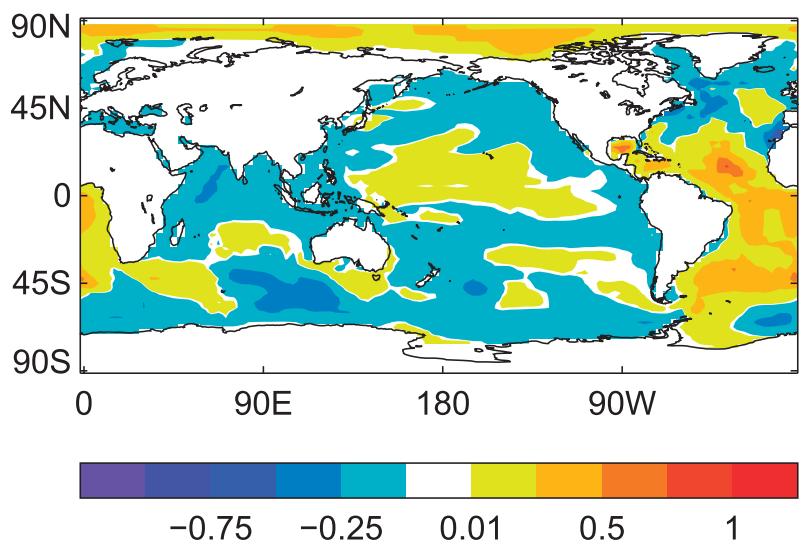

FIG. 9. Thermosteric sea level change (m) when the global mean ocean temperature is back to its initial value at $t=224 \mathrm{yr}$. The scenario followed is $1 \% \mathrm{CO}_{2}$ for $140 \mathrm{yr}$, then $0.5 \times \mathrm{CO}_{2}$.

side effects, while a large negative forcing would produce a climate colder than the preindustrial. Even if sea level returned to its preindustrial global mean, the geographical pattern would be different from the initial one because the penetration of heat is different during warming and cooling.

We have interpreted the behavior of thermal expansion in the AOGCM by comparison with a range of simpler models. The important qualitative difference between surface temperature and sea level is that the former depends on the prevailing radiative forcing and hence the cumulative $\mathrm{CO}_{2}$ emission, while the latter depends on the time integral of radiative forcing and hence the time profile of $\mathrm{CO}_{2}$ emission. The reversibility of thermal expansion cannot be explained without this distinction, which arises because surface temperature relates to the temperature of the upper ocean only, and thermal expansion to the full depth of the ocean. The AOGCM shows that sea level rise and fall are not symmetrical with respect to forcing. When the radiative forcing is reduced, heat leaves the ocean more readily than it entered. This is partly due to the vertical profile of the ocean temperature change, which retains a memory of the time profile of radiative forcing, and partly due to the dependence of vertical heat transport processes on temperature gradients. The success of the stepresponse model in largely reproducing the AOGCM results indicates that this method could be a useful way to continue investigations into AOGCM ocean heat uptake in a scenario-independent way although consideration of the nonlinear behavior may be necessary.

Acknowledgments. We thank A. Pardaens and P. Good for helpful discussion, and three anonymous reviewers for their constructive comments that helped improve the manuscript. J A. Lowe acknowledges support from the 
AVOID programme (DECC and Defra) under contract GA0215. The research leading to these results has received funding from the European Research Council under the European Community's Seventh Framework Programme (FP7/2007-2013), ERC Grant Agreement 247220 , project "Seachange."

\section{REFERENCES}

Allen, M. R., D. J. Frame, C. Huntingford, C. D. Jones, J. A. Lowe, M. Meinshausen, and N. Meinshausen, 2009a: Warming caused by cumulative carbon emissions towards the trillionth tonne. Nature, 458, 1163-1166, doi:10.1038/nature08019.

— Change, 3, 56-58, doi:10.1038/climate.2009.38.

Bowerman, N. H. A., D. J. Frame, C. Huntingford, J. A. Lowe, and M. R. Allen, 2011: Cumulative carbon emissions, emissions floors and short-term rates of warming: Implications for policy. Philos. Trans. Roy. Soc., 369A, 45-66, doi:10.1098/rsta. 2010.0288.

Charbit, S., D. Paillard, and G. Ramstein, 2008: Amount of $\mathrm{CO}_{2}$ emissions irreversibly leading to the total melting of Greenland. Geophys. Res. Lett., 35, L12503, doi:10.1029/2008GL033472.

Church, J. A., and Coauthors, 2011: Revisiting the Earth's sea-level and energy budgets from 1961 to 2008. Geophys. Res. Lett., 38, L18601, doi:10.1029/2011GL048794.

Eby, M., K. Zickfeld, A. Montenegro, D. Archer, K. J. Meissner, and A. J. Weaver, 2009: Lifetime of anthropogenic climate change: Millennial time scales of potential $\mathrm{CO}_{2}$ and surface temperature perturbations. J. Climate, 22, 2501-2511.

Friedlingstein, P., and Coauthors, 2006: Climate-carbon cycle feedback analysis: Results from the $\mathrm{C}^{4} \mathrm{MIP}$ model intercomparison. J. Climate, 19, 3337-3353.

Frölicher, T. L., and F. Joos, 2010: Reversible and irreversible impacts of greenhouse gas emissions in multi-century projections with the NCAR global coupled carbon cycle-climate model. Climate Dyn., 35, 1439-1459, doi:10.1007/s00382-0090727-0.

Gillett, N. P., V. K. Arora, K. Zickfeld, S. J. Marshall, and W. J. Merryfield, 2011: Ongoing climate change following a complete cessation of carbon dioxide emissions. Nat. Geosci., 4, 83-87, doi:10.1038/ngeo1047.

Gloor, M., J. L. Sarmiento, and N. Gruber, 2010: What can be learned about carbon cycle climate feedbacks from the $\mathrm{CO}_{2}$ airborne fraction? Atmos. Chem. Phys., 10, 7739-7751, doi:10.5194/acp-10-7739-2010.

Good, P., J. M. Gregory, and J. A. Lowe, 2011: A step-response simple climate model to reconstruct and interpret AOGCM projections. Geophys. Res. Lett., 38, L01703, doi:10.1029/ 2010 GL045208.

Gordon, C., C. Cooper, C. A. Senior, H. Banks, J. M. Gregory, T. C. Johns, J. F. B. Mitchell, and R. A. Wood, 2000: The simulation of SST, sea ice extents and ocean heat transports in a version of the Hadley Centre coupled model without flux adjustments. Climate Dyn., 16, 147-168.

Gregory, J. M., 2000: Vertical heat transports in the ocean and their effect on time-dependent climate change. Climate Dyn., 16, 501-515, doi:10.1007/s003820000059.

, and J. F. B. Mitchell, 1997: The climate response to $\mathrm{CO}_{2}$ of the Hadley Centre coupled AOGCM with and without flux adjustment. Geophys. Res. Lett., 24, 1943-1946, doi:10.1029/ 97GL01930.
, and P. M. Forster, 2008: Transient climate response estimated from radiative forcing and observed temperature change. J. Geophys. Res., 113, D23105, doi:10.1029/2008JD010405.

—, C. D. Jones, P. Cadule, and P. Friedlingstein, 2009: Quantifying carbon-cycle feedbacks. J. Climate, 22, 5232-5250.

Held, I. M., M. Winton, K. Takahashi, T. Delworth, F. Zeng, and G. K. Vallis, 2010: Probing the fast and slow components of global warming by returning abruptly to preindustrial forcing. J. Climate, 23, 2418-2427.

Huybrechts, P., H. Goelzer, I. Janssens, E. Driesschaert, T. Fichefet, H. Goosse, and M.-F. Loutre, 2011: Response of the Greenland and Antarctic ice sheets to multi-millennial greenhouse warming in the earth system model of intermediate complexity LOVECLIM. Surv. Geophys., 32, 397-416, doi:10.1007/s10712011-9131-5.

Joos, F., M. Bruno, R. Fink, U. Siegenthaler, T. F. Stocker, C. Le Quéré, and J. L. Sarmiento, 1996: An efficient and accurate representation of complex oceanic and biospheric models of anthropogenic carbon uptake. Tellus, 48B, 397-417, doi:10.1034/ j.1600-0889.1996.t01-2-00006.x.

Knorr, W., 2009: Is the airborne fraction of anthropogenic $\mathrm{CO}_{2}$ emissions increasing? Geophys. Res. Lett., 36, L21710, doi:10.1029/2009GL040613.

Lowe, J. A., J. M. Gregory, J. K. Ridley, P. Huybrechts, R. J. Nicholls, and M. Collins, 2006: The role of sea-level rise and the Greenland ice sheet in dangerous climate change: Implications for the stabilisation of climate. Avoiding Dangerous Climate Change, H. J. Schellnhuber et al., Eds., Cambridge University Press, 29-36.

Manabe, S., R. J. Stouffer, M. J. Spelman, and K. Bryan, 1991: Transient responses of a coupled ocean-atmosphere model to gradual changes of atmospheric $\mathrm{CO}_{2}$. Part I: Annual mean response. J. Climate, 4, 785-818.

Marčelja, S., 2010: The timescale and extent of thermal expansion of the global ocean due to climate change. Ocean Sci., 6, 179184.

Matthews, H. D., N. P. Gillett, P. A. Stott, and K. Zickfeld, 2009: The proportionality of global warming to cumulative carbon emissions. Nature, 459, 829-832, doi:10.1038/nature08047.

Meehl, G. A., W. M. Washington, W. D. Collins, J. M. Arblaster, A. Hu, L. E. Buja, W. G. Strand, and H. Teng, 2005: How much more global warming and sea level rise? Science, 307, 1769-1772, doi:10.1126/science.1106663.

Moss, R. H., and Coauthors, 2010: The next generation of scenarios for climate change research and assessment. Nature, 463, 747756, doi:10.1038/nature08823.

Pardaens, A. K., J. M. Gregory, and J. A. Lowe, 2011: A model study of factors influencing projected changes in regional sea level over the twenty-first century. Climate Dyn., 36, 20152033, doi:10.1007/s00382-009-0738-x.

Plattner, G.-K., and Coauthors, 2008: Long-term climate commitments projected with climate-carbon cycle models. J. Climate, 21, 2721-2751.

Raper, S. C. B., J. M. Gregory, and R. J. Stouffer, 2002: The role of climate sensitivity and ocean heat uptake on AOGCM transient temperature response. J. Climate, 15, 124-130.

Ridley, J., J. M. Gregory, P. Huybrechts, and J. Lowe, 2009: Thresholds for irreversible decline of the Greenland ice sheet. Climate Dyn., 35, 1049-1057, doi:10.1007/s00382-0090646-0.

Russell, G. L., V. Gornitz, and J. R. Miller, 2000: Regional sea-level changes projected by the NASA/GISS atmosphere-ocean model. Climate Dyn., 16, 789-797, doi:10.1007/s003820000090. 
Shepherd, J., and Coauthors, 2009: Geoengineering the climate: Science, governance and uncertainty. Royal Society Rep., 81 pp. [Available online at http://royalsociety.org/policy/ publications/2009/geoengineering-climate/.]

Smith, R. S., J. M. Gregory, and A. Osprey, 2008: A description of the FAMOUS (version XDBUA) climate model and control run. Geosci. Model Dev., 1, 53-68, doi:10.5194/gmd-1-53-2008.

Solomon, S., G.-K. Plattner, R. Knutti, and P. Friedlingstein, 2009: Irreversible climate change due to carbon dioxide emissions. Proc. Natl. Acad. Sci. USA, 106, 1704-1709, doi:10.1073/ pnas.0812721106.

Stouffer, R. J., and S. Manabe, 1999: Response of a coupled oceanatmosphere model to increasing atmospheric carbon dioxide: Sensitivity to the rate of increase. J. Climate, 12, 2224-2237.

Vizcaíno, M., U. Mikolajewicz, J. Jungclaus, and G. Schurgers, 2010: Climate modification by future ice sheet changes and consequences for ice sheet mass balance. Climate Dyn., 34, 301-324, doi:10.1007/s00382-009-0591-y.

Zickfeld, K., M. Eby, H. D. Matthews, and A. J. Weaver, 2009: Setting cumulative emissions targets to reduce the risk of dangerous climate change. Proc. Natl. Acad. Sci. USA, 106, 16 129-16 134, doi:10.1073/pnas.0805800106.

V. K. Arora, and N. P. Gillett, 2012: Is the climate response to $\mathrm{CO}_{2}$ emissions path dependent? Geophys. Res. Lett., 39, L05703, doi:10.1029/2011GL050205. 